\title{
Design of a Fault-Tolerant Tandem Converter for a Multi-MW Superconducting Offshore Wind Turbine Generator
}

\author{
Max A Parker and Stephen J Finney \\ Department of Electrical and Electronic Engineering, University of Strathclyde \\ 204 George Street, Glasgow, G1 1XW, UK \\ Email: max.parker@strath.ac.uk, stephen.finney@strath.ac.uk
}

\begin{abstract}
A fault-tolerant tandem converter, based on a current-source converter and cascaded multilevel voltage-source active filter, is proposed as the grid interface for a $10 \mathrm{MW}$ superconducting direct-drive wind turbine generator. The converter reduces the possibility of a short-circuit fault, an issue with the extremely low generator reactance, while having a significantly lower DC capacitance requirement than an equivalent modular multilevel converter, although this is still high due to an extremely low generator frequency. Active filter DC capacitance is optimised, and a control system designed to prevent large DC voltage peaks during transients, and is verified in simulation. DC voltage balancing between the phases of the filter limits the torque control bandwidth of the converter if the capacitance is to be minimised, due to the slow speed of the balancing controller.
\end{abstract}

\section{INTRODUCTION}

In Europe, there is currently a significant interest in offshore wind power, due to the stronger and more consistent wind resource, as well as the limited onshore sites in countries with a high population density. The economics of offshore wind power favour large turbines, of 5MW and higher, and a much greater emphasis on reliability and fault-tolerance due to the difficulty of access for repairs.

Direct-drive generators are attractive for offshore use as they eliminate the step-up gearbox between the turbine rotor and gearbox, which could increase reliability [1] [2]. Unfortunately, studies have shown that the mass and cost of directdrive generators scale badly with turbine size, with the larger diameters needed leading to an extremely high structural mass [3]. Superconducting generators, using superconductors for the generator field windings, allow a higher airgap flux density than permanent-magnet designs, leading to a more compact generator design with lower structural mass [4] [5]. They are under investigation by several companies including General Electric [6], Converteam (now part of GE) [7], ASMC and Siemens. Generator designs also exist which use a superconducting armature winding, but these are not considered in this study. Superconducting generators have several features which present challenges to the design of the power-electronic converter:

- The generators usually employ a slotless design for the rotor and stator, leading to a low reactance, usually around $0.1-0.2$ per-unit. As well as limiting the smoothing of the converter switching harmonics, this also leads to a high short-circuit current, producing a massive generator torque which could damage the generator and turbine rotor.

- Harmonic distortion in the armature currents can lead to $\mathrm{AC}$ losses in the superconducting field coils, which must be removed by the cooling system. This requires a power of around 100 times the losses, due to the extremely low temperature of the superconducting coils.

- The generators have a low pole pitch in order to limit the leakage flux and hence the quantity of expensive superconducting wire, leading to a low AC frequency, as low as $2.5 \mathrm{~Hz}$ at rated speed.

The EU-funded INNWIND project, investigating novel techniques to allow scaling of offshore wind turbines to 10and 20-MW sizes, includes a study of the design of superconducting generators and the associated converter requirements. The most detailed study of superconducting generator design was conducted by General Electric, and specified a 3-level neutral-point-clamped (NPC) voltage-source converter (VSC), operating at $3.3 \mathrm{kV}$ [6]. This type of converter is increasingly commonly being used in industry, and is starting to be used in wind turbines of larger sizes, and is likely to be the most cost effective option. A major disadvantage is that switching device faults can lead to a short-circuit fault, and high generator currents. Such a fault is normally protected against using a high-speed circuit breaker between the generator and converter, but the low frequency of the superconducting generator means that the time until a current zero-crossing, when the current can be interrupted, will be significant, limiting the applicability of this method.

A converter capable of series redundancy would be able to avoid a short-circuit fault in the event of a switching device failure, while also allowing a higher turbine availability. This, along with the requirement for a low current distortion, suggest the use of a modular multilevel converter (MMC) [8] [9], shown in Fig.1(a). A problem with this converter design is that the low generator frequency means that a large DC-link capacitance is required in each converter module, while the larger number of lower rated switching devices increases the cost.

In this paper, the use of a tandem converter is proposed [10] [11] [12]. This uses a current-source converter (CSC) based on cheap and rugged thyristors, with shunt active filters 


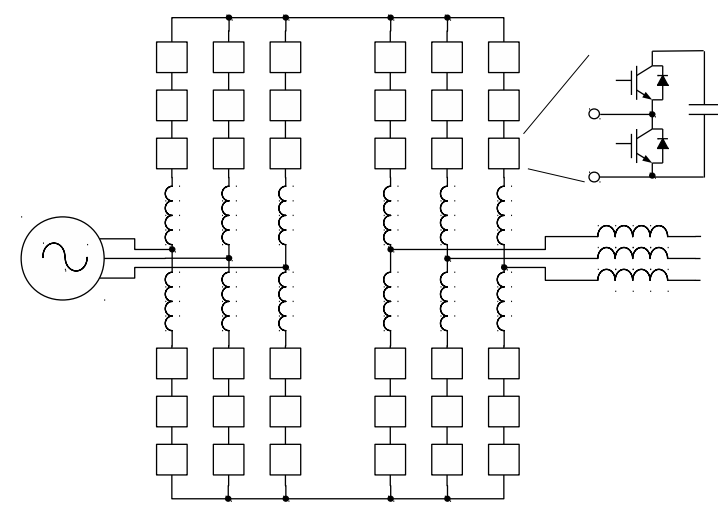

(a)

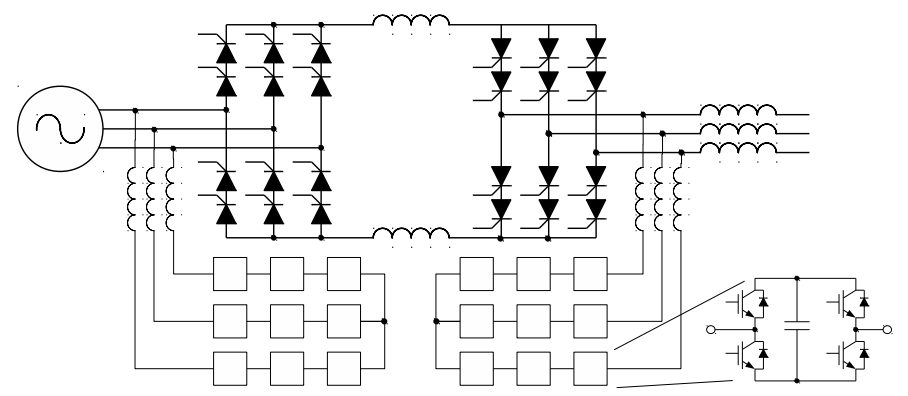

(b)

Fig. 1. Multilevel converter designs. (a) Modular multilevel converter (MMC), (b) Tandem converter.

based on cascaded multilevel inverters to provide a smooth current waveform, and is shown in Fig.1(b). The active filters in a tandem converter are typically rated at around $25 \%$ of the converter power, leading to a lower DC-link capacitance requirement. In addition, the filter current waveform consists mainly of the higher harmonics of the CSC current, further reducing the capacitance requirement. The DC-link energy storage requirements for an MMC and the proposed tandem converter are shown in Table I for a $10 \%$ DC voltage ripple at rated power and $2.5 \mathrm{~Hz} \mathrm{AC}$ frequency. The DC energy storage for an NPC converter with $1 \%$ voltage ripple is shown for comparison, although for such a converter the capacitance is likely to be determined by the ripple current requirements. Both the $\mathrm{CSC}$ and active filter can include redundancy by increasing the number of series devices and modules respectively, with fault tolerant cascaded multilevel converters covered extensively in literature [13] [14] [15] [16].

In the CSC, a $3.3 \mathrm{kV}$ converter will typically use $6 \mathrm{kV}$ thyristors, using two in series, and this will be increased to three series devices for redundancy. For the active filter, the loss of one series module will result in a reduced voltage capability, limiting the turbine speed if the fault is on the machine side. For the grid side filter one or more redundant series modules will need to be included in each phase string.

PWM current-source converters, based on selfcommutating IGCTs or GTOs, have also been proposed for use in large wind turbines [17]. A major disadvantage is the requirement for AC-side filter capacitors, which on the grid side will produce a significant quantity of reactive power which must be absorbed by the grid side converter. This results in a minimum possible DC-link current [18],
TABLE I. COMPARISON OF MMC AND TANDEM CONVERTER DC ENERGY STORAGE REQUIREMENTS

\begin{tabular}{c|c|c|c}
\hline Converter & Generator Side & Grid Side & Total \\
\hline MMC & $14,380 \mathrm{~kJ}$ & $719 \mathrm{~kJ}$ & $15,090 \mathrm{~kJ}$ \\
Tandem & $1,258 \mathrm{~kJ}$ & $199 \mathrm{~kJ}$ & $1,457 \mathrm{~kJ}$ \\
NPC & - & - & $507 \mathrm{~kJ}$ \\
\hline
\end{tabular}

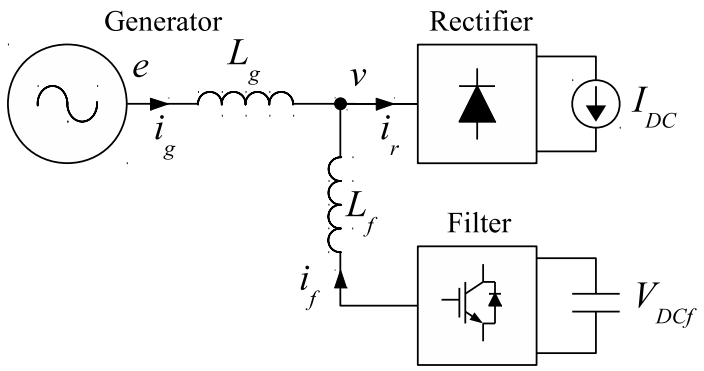

Fig. 2. Single line diagram of the generator-side converter and active filter

leading to high losses and low converter efficiency at low wind speeds.

The tandem converter presented here differs from others presented in literature due to the use of the cascaded multilevel converter as an active filter as opposed to a two-level converter, which presents greater control and design challenges, but allows potentially higher voltage operation and series fault tolerance. Some tandem converter designs also couple the motor- and grid side VSC DC-links, which simplifies DC voltage regulation [12], but is not possible in this case due to the requirement for many isolated DC-links in the cascaded converter design.

This paper will first cover the optimisation of the active filter design, in terms of module capacitance and number of modules, to achieve the lowest active filter cost. The control strategy of the converter will then be described, along with simulation results. The fault tolerance of the converter will be discussed. Finally, grid fault ride-through issues will be discussed briefly, a full analysis being outside the scope of this paper. The paper will mostly concentrate on the generator-side of the converter, due to the aforementioned generator issues. On the grid side, the DC capacitance size requirement in the active filters is much smaller, so increasing the capacitance to allow for transient voltages from torque demand changes will be much cheaper.

\section{ACtive Filter Design Optimisation}

The extremely low generator frequency means that a large DC-link capacitance is required in the filter modules in order to limit the DC voltage ripple, and it is desirable to limit the capacitance to reduce the size and cost of the converter. A single line diagram of the generator side of the converter is shown in Fig.II. The generator produces an EMF $e$ proportional to the generator speed, and has an inductance $L_{g}$, with a current $i_{g}$ flowing, and the voltage at the generator terminals is $v$. The active filter has an overall DC voltage of $V_{D C f}$, supplies a current $i_{f}$, and is connected through a small inductance $L_{f}$ which will be ignored in the calculations. The main converter has a DC-link current of $I_{D C}$ and the rectifier draws a current $i_{r}$. 
TABLE II. ACTIVE FILTER ENERGY VARIATION PER PHASE

\begin{tabular}{c|c}
\hline Filter & $\Delta E(\mathrm{~J})$ \\
\hline Generator Side & 62,436 \\
Grid Side & 9,877 \\
\hline
\end{tabular}

In operation, the active filter is controlled to set the magnitude of the generator terminal voltage equal to the EMF, so the generator current phasor is in between those of the generator EMF and terminal voltage. This gives the best utilisation of the generator and power electronics. The terminal voltage is given by (1), where $E$ is the RMS phase EMF, $\omega t$ the generator electrical angle and $\delta$ is the power factor angle. The rectifier current $i_{r}$ is approximated as a square wave, of magnitude $I_{D C}$ and a conduction angle of $120^{\circ}$, given by (2), and the desired generator current $i_{g}^{\star}$ is given by (3).

$$
\begin{gathered}
v=\sqrt{2} E \sin (\omega t+2 \delta) \\
i_{r}= \begin{cases}I_{D C} & \frac{\pi}{6}<\omega t+2 \delta<\frac{5 \pi}{6} \\
-I_{D C} & \frac{7 \pi}{6}<\omega t+2 \delta<\frac{11 \pi}{6} \\
0 & \text { otherwise }\end{cases} \\
i_{g}^{\star}=\sqrt{2} I_{g}^{\star} \sin (\omega t+\delta)
\end{gathered}
$$

The DC current is controlled so that the there is no net power flow into the active filter, and the required DC current is approximately given by (4). The filter current is given by (5). The variation in stored energy per phase string $\Delta E$ in the filter is found by integrating the product of the filter voltage and current, shown in (6).

$$
\begin{gathered}
I_{D C}^{\star} \approx \frac{\pi}{\sqrt{6}} I_{g}^{\star} \\
i_{f}=i_{r}-i_{g}^{\star} \\
\Delta E=\int v i_{f} d \omega t
\end{gathered}
$$

A similar process is used for the grid side, with the difference being that the filter is controlled to achieve unity power factor output at the grid side of the coupling inductor, and the thyristor inverter will have a delay angle which depends on the turbine speed and output power. For both the generator and grid side filters, $\Delta E$ was calculated by numerically integrating (6) at different wind speeds and taking the differences between the high and low values. Additionally, for the grid side converter the energy associated with absorbing the 6th harmonic ripple from the rectifier was added. The energy variation is given in Table II.

The energy stored in a capacitor is given by (7), which leads to the minimum capacitance per module given by (8) based on minimum and maximum allowed capacitor voltage, where $n$ is the number of series modules per phase. In this case, the maximum DC voltage for each module is set as the rated voltage of the chosen DC-link capacitors, while

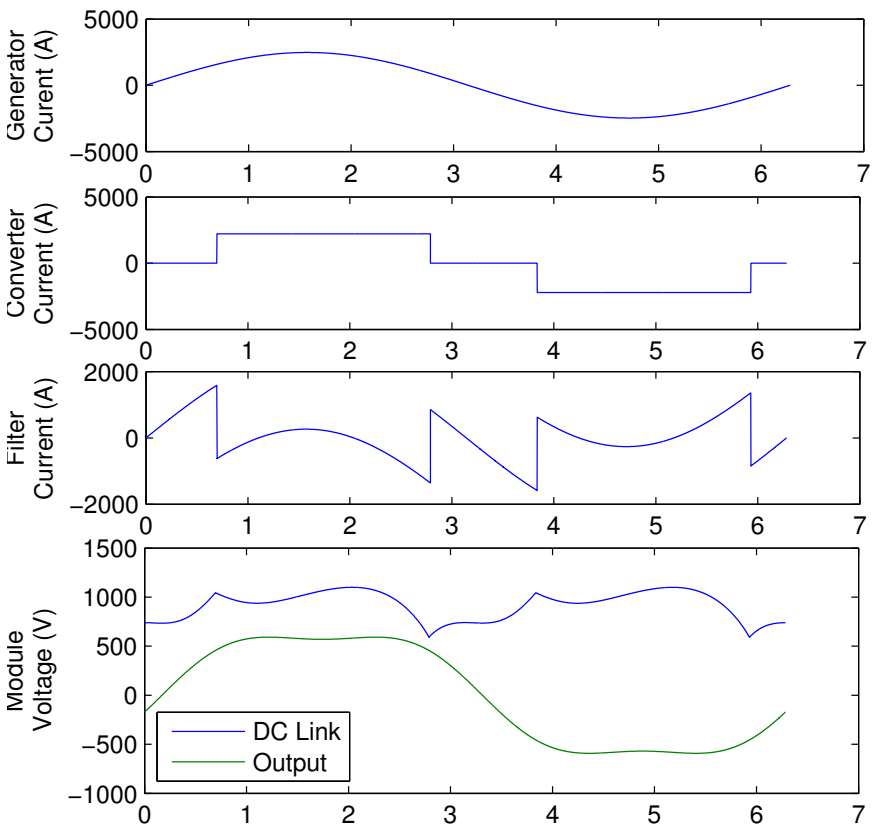

Fig. 3. Generator side converter currents and filter voltages

the minimum voltage is given by the maximum filter phase voltage divided by the number of series modules per phase $n$, given by (9), which assumes the use of $12.5 \%$ third harmonic injection to maximise the DC voltage utilisation. It may be desirable to reduce the maximum DC voltage to allow for transient voltage rises, and it is also be possible to have a lower minimum voltage as the lowest point in the DC voltage waveform does not coincide with the peak filter voltage, which has been demonstrated in MMC-type converters, but this will not be considered at this stage.

$$
\begin{gathered}
E=\frac{1}{2} C V^{2} \\
C_{\text {min }}=\frac{2 \Delta E}{n\left(V_{D C \max }^{2}-V_{D C \min }^{2}\right)} \\
V_{D C \min }=\frac{0.875 \frac{\sqrt{2}}{\sqrt{3}} V_{g}}{n}
\end{gathered}
$$

Fig.3 shows the average generator, converter and filter currents, calculated according to (3), (2) and (5) and the module DC-link voltage and output voltage for four series modules using the minimum capacitance. A slightly higher DC-link voltage ripple could be tolerated, particularly if the phase of the third harmonic injection in the output voltage is shifted to reduce the output voltage when the DC-link voltage is lowest, similar to a method proposed for modular multilevel converters [19].

From (8) and (9), it can be seen that increasing the number of series modules will reduce the minimum DC voltage as well as the energy ripple per module, which allows a smaller module capacitance as well as a smaller total capacitance. However as the number and rating of switching devices 


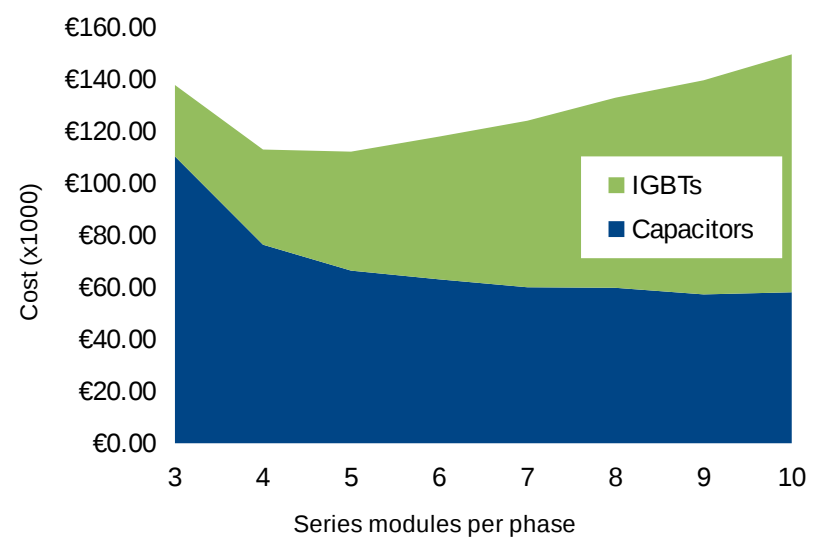

Fig. 4. Active filter cost breakdown for different numbers of modules

per module remains the same, the overall switching device cost will increase and eventually cancel out the reduction in capacitor cost.

Costs for the active filter were calculated based on catalogue prices from a major component supplier. The capacitor used is a polypropylene device, with a voltage rating of $1100 \mathrm{~V}$ and a capacitance of $530 \mu \mathrm{F}$, with a unit cost of $€ 92$. The required capacitance is obtained by varying the number of parallel capacitors. The IGBT used has a voltage rating of $1100 \mathrm{~V}$ and a current rating of $1800 \mathrm{~A}$ and a cost of $€ 762$, with four required per module. It is an isolated base module, and while a press-pack type device would be more appropriate for this application these are currently more expensive and less readily available. The IGBT current rating was chosen to be greater than the peak current conducted by the active filter. This is due to the low switching frequency of the filter (around $50 \mathrm{~Hz}$ ), and the low generator frequency, which means that the device thermal inertia will provide minimal smoothing of the device temperature fluctuations.

The breakdown of the filter costs is given in Fig.4, and shows an initial sharp reduction in capacitor cost as the number of modules is increased, and a steady increase in IGBT cost. The lowest cost is achieved with 4 or 5 series modules, but it is likely that the modules will have additional fixed costs per module such as heatsinks, gate drivers and mechanical components, so a lower number would be preferable. On the other hand, a higher module number might be better for fault tolerance, and would lead to smaller and lighter modules, making them more easy to replace after failure.

\section{Converter Control Strategy}

Control of the tandem converter is divided into two parts: control of the generator current and hence torque, and control of the DC-link voltage and current of the active filter and main converter respectively. In this study, the control system has been analysed at the turbine rated power and speed, as it is here that the DC-link voltage and current control is most critical.

\section{A. Generator Current Control}

The generator current is entirely regulated using the active filter, with the DC current of the main converter controlled to regulate the power balance between the main converter

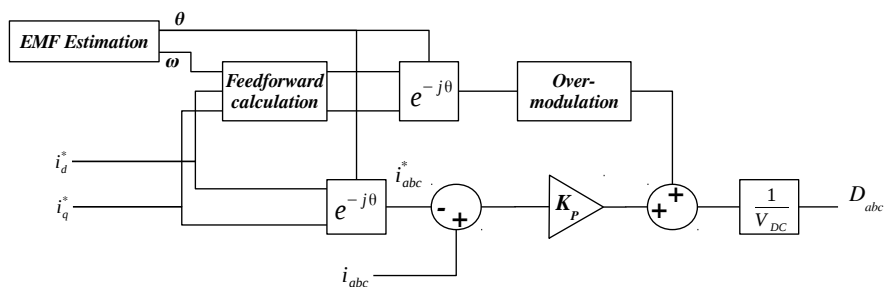

Fig. 5. Generator current controller structure

and filter, and hence the filter DC-link voltage. The current controller is relatively simple, and is based on a calculation of the applied voltage to achieve the required current in the steady state, calculated in the rotating reference frame. This is combined with a proportional controller operating in the fixed reference frame, which speeds up changes in current demand and ensures the current path is properly diverted between the main converter and active filter during main converter commutations.

The structure of the current controller is shown in Fig.5, where the EMF angle and frequency $\Theta, \omega$ are either estimated from the generator applied voltage and resulting current, or calculated from an encoder. From the desired d- and q-axis currents $i_{d}^{*}, i_{q}^{*}$ the feedforward voltage $V_{f f d}, V_{f f q}$ is calculated using (10), where $L$ and $R$ are the generator inductance and resistance, and $k$ is the EMF constant. The feedforward voltage is over-modulated using third harmonic injection.

$$
\begin{aligned}
{\left[\begin{array}{l}
V_{f f d} \\
V_{f f q}
\end{array}\right]=} & {\left[\begin{array}{c}
0 \\
k \omega
\end{array}\right]+\left[\begin{array}{cc}
R & 0 \\
0 & R
\end{array}\right]\left[\begin{array}{l}
I_{d}^{*} \\
I_{q}^{*}
\end{array}\right] } \\
& +\left[\begin{array}{cc}
0 & -\omega L \\
\omega L & 0
\end{array}\right]\left[\begin{array}{c}
I_{d}^{*} \\
I_{q}^{*}
\end{array}\right]
\end{aligned}
$$

A control system with higher dynamic performance has been shown in literature [11], but this uses a force-commutated main converter, with a fast response time. In this case, dynamic performance is limited by the speed of the main converter DC-current regulation, which is limited by the size of the DC inductor. For a large wind turbine, a high torque control bandwidth is not required, and for a superconducting generator a fast rate of armature current change could induce harmonics in the superconducting field windings, leading to losses there.

\section{B. DC-Link Current and Voltage Control}

The DC-link current of the main converter is controlled by varying the average DC voltage $V_{D}$ of the grid-side inverter through the firing angle, $\alpha$, with the DC voltage given by (11), where $V_{L L}$ is the grid line-line voltage. The desired voltage, $V_{D}^{*}$ is calculated as shown in Fig.6). The DC-link current, $i_{D C}$, is filtered using a moving average filter to remove the ripple from the grid-side inverter at six times the grid frequency, subtracted from the desired current $i_{D C}^{*}$ and fed to a PI controller. The output of the controller is subtracted from the generator side DC voltage, found by subtracting the smallest generator terminal voltage from the largest, the generator voltages having been calculated by the generator current controller. $V_{D}^{*}$ is used to calculate $\alpha$ according to (11). As the generator side DC voltage used here includes the 6th 


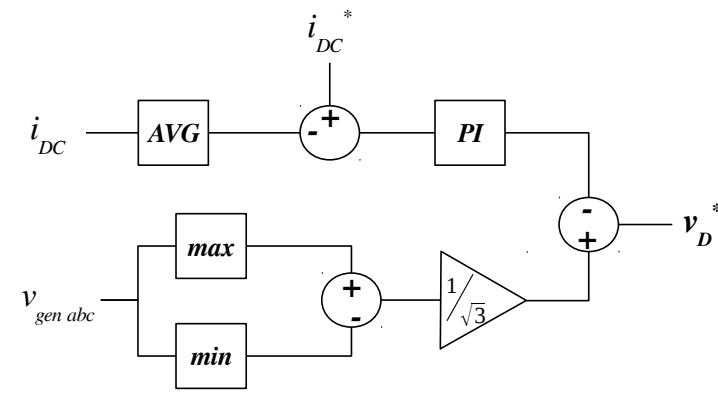

Fig. 6. Main converter DC-link current controller

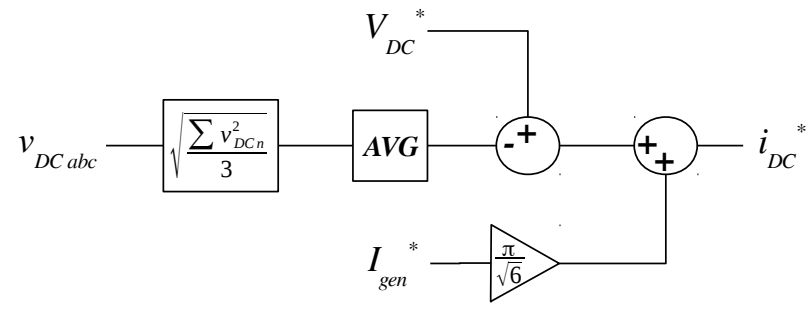

Fig. 7. Active filter overall DC voltage controller

harmonic ripple, then this ripple will be largely eliminated from the DC-link current and passed through the grid inverter, where it will be absorbed by the grid-side active filter. This reduces the size of DC-link smoothing inductor required.

$$
V_{D}=V_{L L} \frac{3 \sqrt{2}}{\pi} \cos \alpha
$$

For the cascaded multilevel active filter, control of the DC link voltage consists of three aspects: overall DC voltage, phase to phase voltage balancing and inter-module voltage balancing. The inter-module balancing is an established problem with documented solutions [20] [21] [22] [23], and will not be considered here.

For the overall voltage regulation, for a given generator current demand the required DC current in the main converter is approximately given by (4), and this value is used as a feedforward term as shown in Fig.7. Overall DC voltage is obtained by summing the total voltages of the three phase strings and dividing by three. This is then filtered with a variable averaging filter to remove the voltage ripple, which will be at the sixth harmonic of the generator frequency, and used with a PI controller. The low generator frequency of $2.5 \mathrm{~Hz}$ means that the sixth harmonic is only $15 \mathrm{~Hz}$ at rated speed, which places severe limits on the PI controller bandwidth, meaning that the response speed of the controller is reliant on the feedforward terms for a fast response speed, with the PI controller used for small adjustments. The filter also means that the chosen PI controller parameters will not be suitable for operation at lower wind speeds, where the generator frequency is lower, so the controller will need to switch to a different set of parameters.

It was found that the response speed of the generator current controller was considerably greater than that of the DC-link current controller, with the result that in the initial generator current rise the generator terminal voltage is held at
TABLE III. CONVERTER SIMULATION PARAMETERS

\begin{tabular}{l|l}
\hline Generator Power & $10 \mathrm{MW}$ \\
Generator Voltage & $3300 \mathrm{~V}$ \\
Generator Inductance & $21.6 \mathrm{mH}$ \\
Filter Series Modules & 4 \\
Filter switching frequency & $50 \mathrm{~Hz}$ \\
Filter module capacitance & $120 \mathrm{mF}$ \\
DC-link Inductance & $23 \mathrm{mH}$ \\
Grid Voltage & $3500 \mathrm{~V}$ \\
\hline
\end{tabular}

a low value, which prevents the DC-link current from rising. This delay in the DC-link current rise causes a large filter DC-link over-voltage. Because of this, a first-order filter with a time constant of $15 \mathrm{~ms}$ is used on the generator current demand signal to slow down the generator current rise.

The inter-phase DC voltage balance is controlled by adjusting the current demand for the different phases of the generator, which is achieved by adding a negative phase sequence to the current controller demand signals $i_{a b c}^{*}$ in Fig.5. This is achieved using the controller shown in Fig.8, in which the individual phase DC-link voltages are first filtered using a moving average filter, before being converted to the 2phase equivalent, with a proportional controller used to set the negative phase sequence d- and q-axis currents to control $V_{D C \alpha}$ and $V_{D C \beta}$, representing the unbalance, to zero.

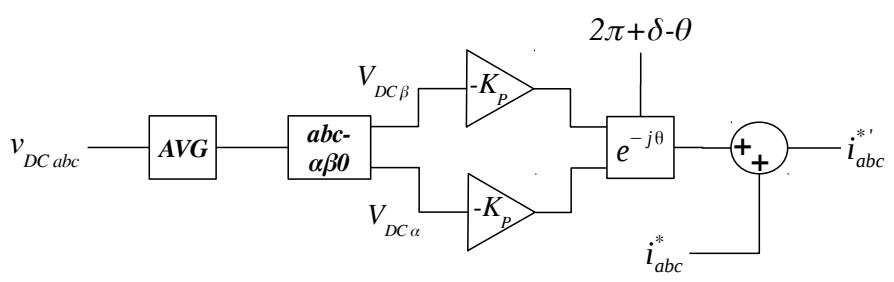

Fig. 8. Inter-phase DC-link voltage balancing controller

The unbalanced generator current will result in some torque ripple, which is undesirable but will only be significant during large unbalances. A better solution might be to vary the firing angles of the rectifier thyristors between phases, but this is more complicated to implement.

\section{Simulation Results}

Simulations were carried out using Simulink, using the SimPowerSystems blockset. Parameters for the simulated converter and generator are given in Table III. For the purposes of the simulation, the active filter DC links were represented as constant voltage sources, with the dynamic DC voltage estimated by integrating the power flows into and out of the filter. This allows problems with DC voltage regulation to be identified without them affecting the rest of the simulation. The filter module capacitance is set at around three times the minimum value calculated earlier, to reduce the effects of voltage imbalance between phases on the control system.

Simulated steady state current in the generator, rectifier and filter are shown in Fig.9, with the inter-phase DC voltage balancing controller de-activated, and shows strong agreement with the calculated currents in Fig.3. The response of the converter to a step change in generator current demand is shown in Fig.10. Generator current response is fast, as is the corresponding increase in DC-link current, but the filter overall 

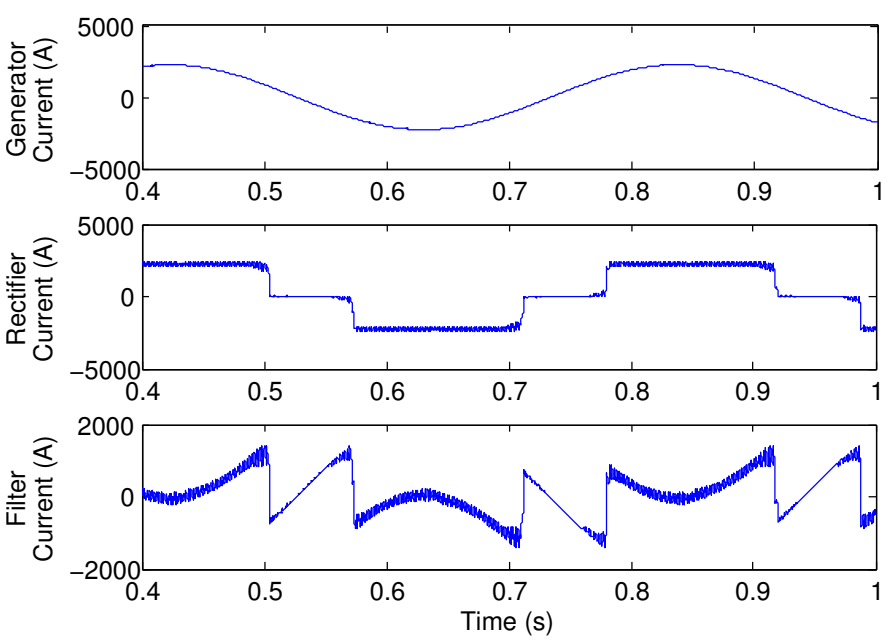

Fig. 9. Simulated generator, rectifier and filter current
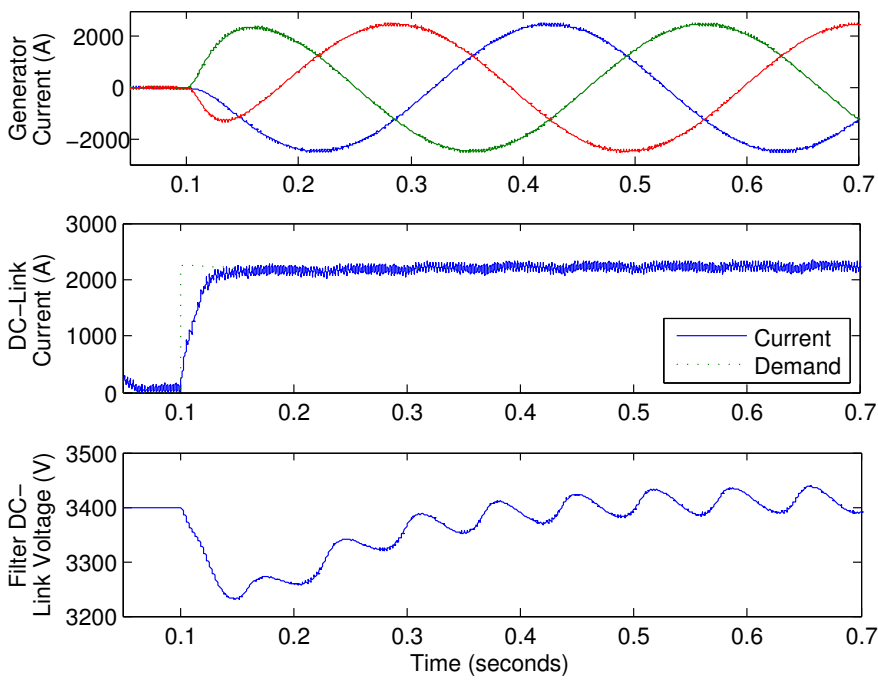

Fig. 10. Response to step in generator current demand

DC voltage shows a distinct dip due to energy being drawn to charge the generator and filter inductances. The DC voltage shows the expected 6th harmonic ripple, but also ripple at the second harmonic due to imbalances in the DC voltage between the phase strings.

The step response of the system with the inter-phase DC voltage balancing controller active is shown in Fig.11. The DC-link voltages of the three phase strings of the filter show a large unbalance after the initial current step, due to the fact that all phases start at the same average step but have different voltage trajectories. The balancing controller is able to balance the phases within around half a second, but the speed is limited by the filtering needed on the DC voltages and the lack of any feedforward terms. A clear generator torque ripple is visible just after the torque step.

It is clear that the need to balance the DC-link voltages of the three phase strings will limit the torque control bandwidth of the converter, although a high bandwidth could be achieved as in the simulations if the module DC-link capacitance is increased to allow the initial transient unbalance. A compromise
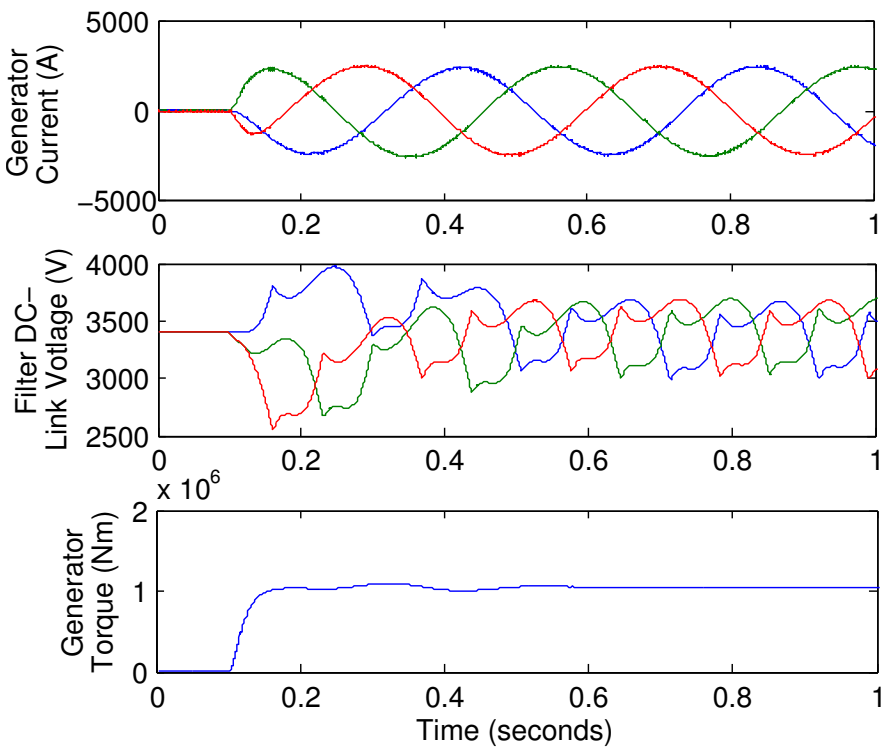

Fig. 11. Phase string DC voltages during current demand step

will need to be reached between torque control bandwidth and module DC-link capacitor size.

\section{CONCLUSIONS AND DISCUSSION}

A fault-tolerant tandem converter, based on a thyristorbased current-source inverter and cascaded multilevel active filter, has been proposed as the grid interface for a $10 \mathrm{MW}$ superconducting direct-drive wind turbine generator. The converter meets the requirements of the generator for short-circuit protection in converter faults and a low distortion current waveform, while significantly reducing the DC-link capacitance requirements, which are high due to the low frequency, compared with the modular multilevel converter.

DC-link capacitance was optimised by increasing the number of series active filter modules above that necessary to meet the voltage rating, which allows a greater DC voltage ripple and smaller capacitance. Module faults will reduce the voltage ripple capability, reducing the generator power.

Controllers have been designed for the generator and DC-link current, filter DC-link voltage and inter-phase DClink voltage balancing. Simulations show a fast response to torque demand signals, but this leads to initially high interphase DC-link voltage unbalance due to the slow response speed of the balancing controller. Reducing the torque control bandwidth significantly will allow the DC voltages to remain balanced, minimising the capacitance requirement. Alternatively, a higher capacitance could be used to accommodate the initial unbalance, allowing a fast torque response.

This converter design could be used with other generator types, although the higher reactance of many direct-drive generators means that the active filter may need to supply a higher reactive power, increasing the rating and reducing the benefits. The converter voltage could easily be increased, and may be useful for transformerless grid interfaces. 


\section{ACKNOWLEDGEMENTS}

The research leading to these results has received funding from the European Community's Seventh Framework Programme FP7-ENERGY-2012-1-2STAGE under grant agreement No.308974 (INNWIND.EU), and the EPSRC's 'Underpinning Power Electronics 2012: Converters Theme' research programme (EP/K035304/1).

\section{REFERENCES}

[1] D. McMillan and G. W. Ault, "Techno-economic comparison of operational aspects for direct drive and gearbox-driven wind turbines," IEEE Trans. Energy Convers., vol. 25, no. 1, pp. 191-198, Mar. 2010.

[2] P. J. Tavner, F. Spinato, G. J. W. van Bussel, and E. Koutoulakos, "Reliability of different wind turbine concepts with relevance to offshore application," in International Wind Energy Conference, EWEC2008, Brussels, Apr. 2008.

[3] A. S. McDonald, M. A. Mueller, and H. Polinder, "Comparison of generator topologies for direct-drive wind turbines including structural mass," in Proc. Int. Conf. Electrical Machines, ICEM, 2006.

[4] A. Abrahamsen, N. Mijatovic, E. Seiler, T. Zirngibl, C. Traehold P. B. Norgard, N. F. Pedersen, N. H. Andersen, and J. Ostergard, "Superconducting wind turbine generators," Superconductor Science and Technology, vol. 23, 2010.

[5] H. Polinder, J. A. Ferreira, B. B. Jensen, A. B. Abrahamsen, K. Atallah, and R. A. McMahon, "Trends in wind turbine generator systems," IEEE Trans. Emerg. Sel. Topics Power Electron., vol. 1, no. 3, pp. 174-185, Sep. 2013.

[6] R. Fair, W. Stautner, M. Douglass, R. Rajput-Ghoshal, M. Moscinski, P. Riley, D. Wagner, J. Kim, S. Hou, F. Lopez, K. Haran, J. Bray, T. Laskaris, J. Rochford, and R. Duckworth, "Superconductivity for large scale wind turbines," in Applied Superconductivity Conference, 2012.

[7] C. Lewis and J. Muller, "A direct-drive wind turbine HTS generator," in Power Engineering Society General Meeting, IEEE, 2007.

[8] S. Debnath, J. Qin, B. Bahrani, M. Saeedifard, and P. Barbosa, "Operation, control and applications of the modular multilevel converter: A review," IEEE Trans. Power Electron., vol. 30, no. 1, pp. 37-53, Jan. 2015.

[9] M. A. Perez, S. Bernet, J. Rodriguez, S. Kouro, and R. Lizana, "Circuit topologies, modeling, control schemes, and applications of modular multilevel converters," IEEE Trans. Power Electron., vol. 30, no. 1, pp. 4-17, Jan. 2015.
[10] A. M. Trzynadlowski, F. Blaabjerg, J. K. Pedersen, and N. Patriciu, "The tandem inverter: Combining the advantages of voltage-source and current-source inverters," in Thirteenth Annual Applied Power Electronics Conference, APEC, 1998.

[11] G. Tadmor, "Control of a combined GTO/IGBT drive system for low torque ripple in a large permanent magnet synchronous motor," IEEE Trans. Control Syst. Technol., vol. 12, no. 1, pp. 21-35, 2004.

[12] M. Imecs, A. M. Trzynadlowski, I. I. Incze, and C. Szabo, "Vector control schemes for tandem-converter fed induction motor drives," IEEE Trans. Power Electron., vol. 20, no. 2, Mar. 2005.

[13] M. A. Parker, C. H. Ng, and L. Ran, "Fault tolerant control for a modular generator-converter scheme for direct-drive wind turbines," IEEE Trans. Ind. Electron., vol. 58, no. 1, pp. 305-315, 2011.

[14] J. Rodriguez, P. Hammond, J. Pontt, R. Musalem, P. Lezana, and M. J. Escobar, "Operation of a medium-voltage drive under faulty conditions," IEEE Trans. Ind. Electron., vol. 52, no. 4, pp. 1080-1085, 2005.

[15] P. Lezana, J. Pou, T. A. Meynard, J. P. Rodriguez, S. Ceballos, and F. Richardeau, "Survey on fault operation on multilevel inverters," IEEE Trans. Ind. Electron., vol. 57, no. 7, pp. 2207-2218, Jul. 2010.

[16] B. Mirafzal, "Survay of fault-tolerance techniques for three-phase voltage source inverters," IEEE Trans. Ind. Electron., vol. 61, no. 10, pp. 5192-5202, Oct. 2014.

[17] J. Dai, D. Xu, and B. Wu, "A novel control scheme for current-sourceconverter-based PMSG wind energy conversion systems," IEEE Trans. Power Electron., vol. 24, no. 4, pp. 963-972, Apr. 2009.

[18] M. Popat, B. Wu, and N. R. Zargari, "A novel decoupled interconnecting method for current-source converter-based offshore wind farms," IEEE Trans. Power Electron., vol. 27, no. 10, pp. 4224-4233, Oct. 2012.

[19] K. Ilves, A. Antonopoulos, L. Harnefors, S. Norrga, L. Angquist, and H.-P. Nee, "Capacitor voltage ripple shaping in modular multilevel converters allowing for operating region extension," in 37th Annual Conference of the IEEE Industrial Applications Society, IECON, 2011.

[20] H. Sepahvand, J. Liao, and M. Ferdowsi, "Investigation on capacitor voltage regulation in cascaded H-bridge multilevel converters with fundamental frequency switching," IEEE Trans. Ind. Electron., vol. 58, no. 11 , Nov. 2011

[21] L. Tarisciotti, P. Zanchetta, A. Watson, S. Bifaretti, J. C. Clare, and P. W. Wheeler, "Active DC voltage balancing PWM technique for high-power cascaded multilevel converters," IEEE Trans. Ind. Electron., vol. 61, no. 11, pp. 6157-6167, Nov. 2014.

[22] M. B. de Alvarenga and J. A. Pomilio, "Voltage balancing and commutation suppression in symmetrical cascade multilevel converters for power quality applications," IEEE Trans. Ind. Electron., vol. 61, no. 11, pp. 5996-6003, Nov. 2014.

[23] A. M. Y. M. Ghias, J. Pou, V. G. Agelidis, and M. Ciobotaru, "Voltage balancing method for a flying capacitor multilevel converter using phase disposition PWM," IEEE Trans. Ind. Electron., vol. 61, no. 12, pp. 6538-6546, Dec. 2014. 